\title{
The International Space Station Habitat
}

\section{Patricia Mendoza Watson ${ }^{1}$, Mike Engle}

${ }^{I}$ NASA Johnson Space Center, Houston Texas 77058, Mail Code OM

${ }^{2}$ NASA Johnson Space Center, Houston Texas 77058, Mail Code OM

Abstract. The International Space Station (ISS) is an engineering project unlike any other. The vehicle is inhabited and operational as construction goes on. The habitability resources available to the crew are the crew sleep quarters, the galley, the waste and hygiene compartment, and exercise equipment. These items are mainly in the Russian Service Module and their placement is awkward for the crew to deal with. ISS assembly will continue with the truss build and the addition of International Partner Laboratories. Also, Node 2 and 3 will be added. The Node 2 module will provide additional stowage volume and room for more crew sleep quarters. The Node 3 module will provide additional Environmental Control and Life Support Capability. The purpose of the ISS is to perform research and a major area of emphasis is the effects of long duration space flight on humans, a result of this research they will determine what are the habitability requirements for long duration space flight. 


\title{
The International Space Station Habitat
}

\author{
Patricia Mendoza Watson ${ }^{1}$ and Mike Engle ${ }^{2}$ \\ ${ }^{1}$ NASA, Johnson Space Center, Mail Code OM, Houston TX 77058, 281-483-7770, patricia.watson1@;isc.nasa.gov \\ ${ }^{2}$ NASA, Johnson Space Center, Mail Code OM, Houston TX 77058, 281-244-0904, michael.e.engle1@jsc.nasa.gov
}

\begin{abstract}
The International Space Station (ISS) is an engineering project unlike any other. The vehicle is inhabited and operational as construction goes on. The habitability resources available to the crew are the crew sleep quarters, the galley, the waste and hygiene compartment, and exercise equipment. These items are mainly in the Russian Service Module and their placement is awkward for the crew to deal with. ISS assembly will continue with the truss build and the addition of International Partner Laboratories. Also, Node 2 and 3 will be added. The Node 2 module will provide additional stowage volume and room for more crew sleep quarters. The Node 3 module (not officially in the ISS Program) will provide additional Environmental Control and Life Support Capability. The purpose of the ISS is to perform research and a major area of emphasis is on the effects of long duration space flight on humans, a result of this research they will determine what are the habitability requirements for long duration space flight.
\end{abstract}

\section{Introduction}

The International Space Station, ISS, is in the construction phase. Unlike past space vehicle construction and most likely future space vehicle construction, the ISS is inhabited and operational as assembly progresses. Constructing the vehicle, maintaining functionality, performing research and keeping the crew alive require all the current vehicle resources. Table 1 lists the missions flown to date and the elements they have added to the ISS. Future pressurized volume additions add International Partner Research Capability and Stowage. While the larger work volume is a plus for habitability the resources available to the crew will not change significantly from what they are today.

Table 1. Assembly Sequence Overview, Flown as of June 26, 2002 (NASA FPWG)

\begin{tabular}{|l|l|l|l|l|l|}
\hline & Flight & $\begin{array}{l}\text { Delivered } \\
\text { Elements }\end{array}$ & $\begin{array}{l}\text { Date } \\
\text { Flown }\end{array}$ & Flight & $\begin{array}{l}\text { Delivered } \\
\text { Elements }\end{array}$ \\
\hline 20-Nov-98 & 1A/R & FGB & 28-Apr-01 & 2S & Soyuz TM \\
04-Dec-98 & 2A & Node1, PMA1 & 20-May-01 & 4P & Progress M-1 \\
27-May-99 & 2A.1 & SpaceHab DCM & 12-Jul-01 & 7A & Airlock \\
19-May-00 & 2A.2A & SpaceHab DCM & 10-Aug-01 & 7A.1 & MPLM Lab Racks \\
12-Ju1-00 & 1 & Service Module & 21-Aug-01 & 5P & Progress M \\
06-Aug-00 & 1 & Progress-M1 & 14-Sep-01 & 4R & DC \\
08-Sep-00 & 2A.2B & SpaceHab DCM & 21-Oct-01 & 3S & Soyuz TM \\
11-Oct-00 & 3A & Z1 Truss & 26-Nov-01 & 6P & Progress - M1 \\
31-Oct-00 & 2R & Soyuz TM & 05-Dec-01 & UF-1 & MPLM Lab Racks \\
16-Nov-00 & 2P & Progress M-1 & 21-Mar-02 & 7P & Progress M1 \\
01-Dec-00 & 4A & P6 & 08-Apr-02 & 8A & S0 (MT) \\
07-Feb-01 & 5A & Lab & 25-Apr-02 & 4S & Soyuz TM \\
26-Feb-01 & 3P & Progress M-1 & 05-Jun-02 & UF-2 & MPLM \\
08-Mar-01 & 5A.1 & MPLM Lab Racks & 26-Jun-02 & 8P & Progress M \\
19-Apr-01 & 6A & MPLM Lab Racks & & & \\
\hline
\end{tabular}




\section{Habitability Resources}

Most of the habitability resources on-orbit today are in the Russian Service Module (SM), and the US Laboratory. The Waste Control System (toilet), two, crew sleep quarters, the treadmill and the galley are in the SM. The crew eats, sleeps and exercises in the SM. The Service Module also houses the bulk of the Environmental Control and Life Support System (ECLS). The two main ECLS components in the SM are the Elektron, and the Vozdukh. The Elektron is the oxygen generator, it nominally produces oxygen for 3 crew and it can support up to 6 crew for short periods. The Vozdukh is a $\mathrm{CO} 2$ scrubber; it can support the equivalent of $4.5 \mathrm{crew}$. The Laboratory also has a $\mathrm{CO} 2$ scrubber called the Carbon Dioxide Removal Assembly, CDRA; it can scrub $\mathrm{CO} 2$ for the equivalent of 7 crew. One crew sleep quarters is in the Laboratory. The cycle ergometer vibration isolation system (CEVIS) and the crew health care system is located in the US Laboratory. A Resistive Exercise Device (RED) is in Node 1.

\section{ISS Missions}

As of the end of Summer 2002 the International Space Station Program successfully completed 29 missions. Twenty-one of those missions were for re-supply, and outfitting. Only four of those flights added pressurized volume. This year ISS assembly will continue with the truss build and the addition of photovoltaic modules. This will be followed by the addition of the International Partner Laboratories (NASA MIO, Walton). To date, 5 crews have lived on-board the ISS. Each ISS crew has had basically the same habitability resources available to them in the SM, US Laboratory and the Node 1. The fifth Expedition crew is on-orbit at the time of this writing. The four previous Expedition crews have returned to Earth and have reported on their experience living on board the ISS.

The first, ISS flight, $1 \mathrm{~A} / \mathrm{R}$, put the Functional Cargo Block (FGB) in Orbit. This ISS element is the foundation on which the ISS is being built. It provides power, computing, docking and berthing interfaces. The FGB was a joint venture between the Russian Space Agency and NASA it designated as an A/R flight because it is joint American and Russian element. The second flight, $2 \mathrm{~A}$, installed the Node 1 element. Node 1 is a NASA element designed to function as a connector allowing the ISS to continue to build up in the forward, nadir and zenith direction. The Node 1 houses stowage racks and the Resistive Exercise Device, RED. The next 2 flights were US re-supply flights, 2A.1 and 2A.2A, followed by a Russian flight, 1R. The Service Module was added in the Russian Mission 1R. The Service Module, SM, brought with it the Elektron, an oxygen generator, the Vozdukh, a CO2 scrubber, the galley and the Waste Collection System (toilet). The following mission, 1P, was a Russian re-supply flight. It was followed by another American re-supply flight, 2A.2B. Flight $3 \mathrm{~A}$ was an American flight which brought up the Z-1 Truss (an external element).

\section{Expedition 1}

Flight $2 \mathrm{R}$ was the Russian mission which provided the Soyuz rescue vehicle and brought with it the first Increment Crew or Expedition $1 \mathrm{crew}$. The Expedition 1 crew was on board the ISS for 138 days (NASA) and was there when the Lab was installed and left on the following flight approximately one month later. While they were there, there were 5 flights to the ISS. Flight 2P was a Progress flight which provided more supplies. The first US Photovoltaic Module (PVM) came up on flight $4 \mathrm{~A}$. The US laboratory Module was launched on flight $5 \mathrm{~A}$ on February 7, 2001. It contained Lab system racks and stowage capability. The CEVIS and additional $\mathrm{CO} 2$ scrubbing capability are part of the Lab, the following flight, 3P, was a Progress re-supply flight. Expedition 1 left the ISS on the following flight, 5A.1 (NASA $\mathrm{MIO})$.

For the bulk of their stay the Increment 1 crew lived in the Service Module. They also had access to the FGB and the Node volume. Two crew members slept in the Service Module and one slept on the wall of the FGB. In the crew debrief the crew felt that stowage was an issue for them. They also felt the treadmill in the Lab was always in the way. When a taxi crew was onboard they felt their resources were "extremely over-taxed" (CPWG Exp. 1, SF6 Exp. 1). The Expedition 1 crew had 9,334 cubic feet of volume available to them and 13,146 cubic feet of volume after the US Lab arrived, about the same volume as the former MIR Complex. (Miller).

\section{Expedition 2}

Flight 5A.1 was a crew rotation flight. Expedition 2 arrived along with additional Lab Racks and the Expedition 1 crew came home on that shuttle flight. The Expedition 2 crew was on board the ISS for 167 days (NASA). During their stay 
there were 5 flights to the ISS. Flight $6 \mathrm{~A}$ delivered more Lab Racks, flight $2 \mathrm{~S}$ changed out the Soyuz TM and flight $4 \mathrm{P}$ was a Progress re-supply flights. The US Airlock was launched on flight 7A; the US Airlock provides the capability to perform EVAs from the US side with a minimum loss of air. Expedition 2 left the ISS on flight 7A.1. The vehicle configuration and available volume that was available to Expedition 2 is as shown in Figure 1 (Miller et al). The habitable volume shown in Figure 1 is also that available to the crew today and will remain in this configuration until the truss build is complete and the International Partner Laboratories are launched.

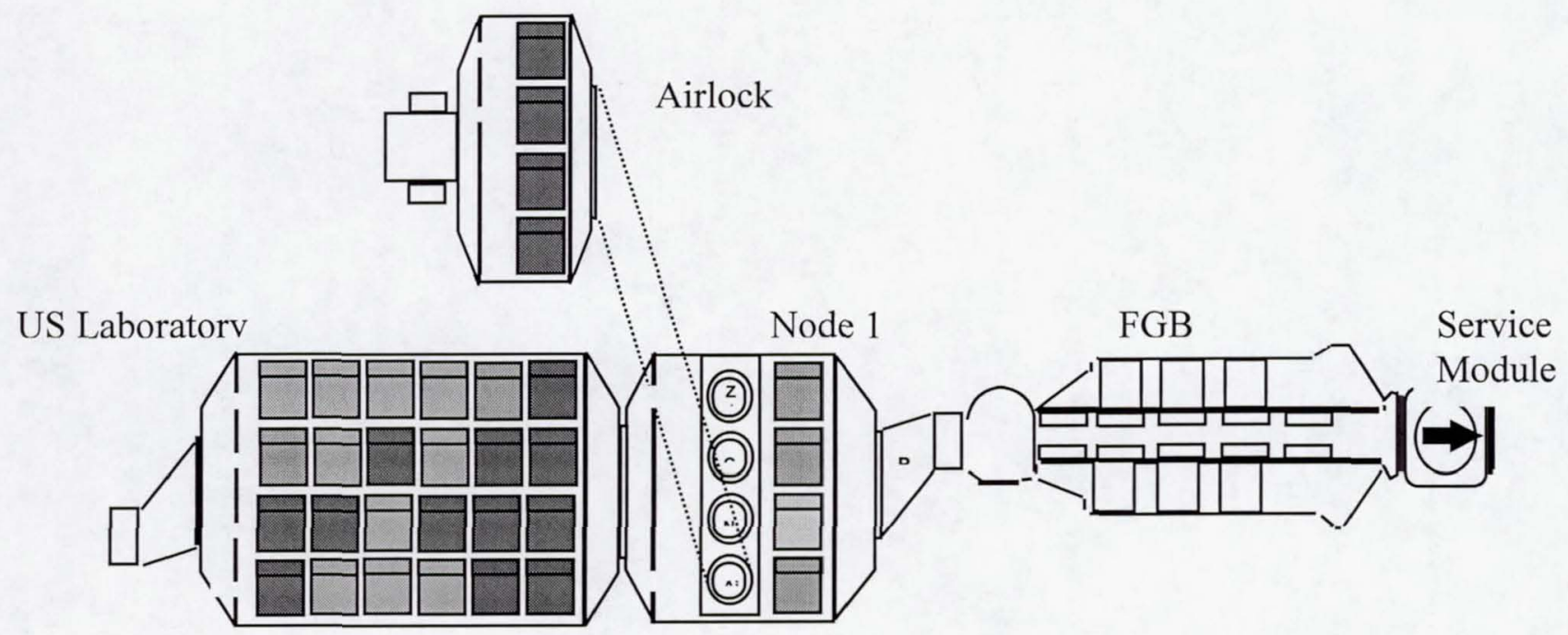

Figure 1. Habitable Volume Today (Miller et al)

The Expedition 2 crew indicated that their top two Habitability issues that affected their comfort, productivity and performance were noise and inter-module communications. The concentration of functions and activities in the SM was an issue. Specifically, the location of the toilet near the sleep areas, dining table and kitchen panty. Also, the treadmill in the middle of the SM living area was a problem as was the location of the CEVIS in the middle of the Lab (SF6 Exp.2, CPWG). The Expedition 2 crew had approximately 13,146 cubic feet of pressurized volume available to them (Miller).

\section{Expedition 3}

Flight 7A.1 was a crew rotation flight. Expedition 3 arrived along with additional Lab racks and the Expedition 2 crew came home. The Expedition 3 crew was on board the ISS for 130 days (NASA). While they were there, there were 5 flights to the ISS. Flight 5P was a Progress re-supply flight. The Russian flight, 4R, brought up the docking compartment and the capability to have a docked Progress and a docked Soyuz which enabled us to rotate a crew while the Progress was docked. It also gave us a backup Soyuz docking location. Progress docking is still limited to the aft end of the FGB. Flight $3 \mathrm{~S}$ brought a new Soyuz to the ISS. Flight $6 \mathrm{P}$ was a Progress re-supply flight. Increment 3 left the ISS on flight UF-1 (NASA MIO).

The Expedition 3 crew indicated that their top habitability issue was that there is no dedicated place to bathe or shower. They bathed in the FGB, which is like a hallway. They did this by closing off the module and cutting off both ends of the ISS. They did this to provide privacy since they had a mixed crew (CPWG Exp. 3, SF6 Exp. 3). The Expedition 3 crew had approximately 14,797 cubic feet of pressurized volume available to them (Miller).

\section{Expedition 4}

Expedition 4 arrived on flight UF-1 and lived on-board the ISS for 195 days (NASA). While they were on-board the ISS there were 4 flights to the ISS. 7P was another Progress re-supply flight. Flight 8A brought up the centerpiece of the power truss the S0. The following flight was a Soyuz change-out flight 4S Soyuz - TM. Expedition 4 left the ISS on flight UF-2 (NASA MIO). 
Their top habitability issues were stowage and the concentration of functions in the SM. The Waste Collection System (toilet), galley, exercise equipment and 2 crew quarters are in the SM (SF6 Exp. 4). The Expedition 4 crew had approximately 14,791 cubic feet of pressurized volume available to them (Miller).

\section{Expedition 5}

The UF-2 MPLM was a crew rotation flight the Expedition $\mathbf{5}$ crew was put in place and Expedition 4 came home. The duration of their stay was 184 days (NASA). At the time this is being written Expedition 5 habitability outbriefs have not been published.

\section{Future Flights}

The purpose of the next set of flights is primarily to build the truss and add photovoltaic modules. Once this is accomplished there will be sufficient power to operate additional laboratories. Prior to the International Partner Lab deliveries, Node 2 will be added on flight 10A. Like Node 1, this module will act as a connector to continue the ISS buildup and provide internal stowage. Then, the European Space Agency Laboratory Module, Columbus will be added. Followed by the National Aerospace Development Agency of Japan Laboratory Module and Storage Module. The Russian Space Agency will provide the MTSM, a multi-purpose pressurized module whose function has not been finalized. One option is to have it provide additional life support capability. Another US addition is the Centrifuge Accommodations Module, CAM, it is a US Laboratory facility for performing research at variable gravity levels. Node 3 and the Cupola are in work but are not shown is the assembly sequence and not officially part of the ISS program. The Cupola has been delivered to Kennedy Space Center and the plan is to attach it to Node 3 and if the Node 3 is not added it will attach to Node 2 . The Node 3 life support systems are also not in the currently in the program, but they are required to support 6 crew. The Life support system is basically, an oxygen generator, a CO2 scrubber and a water recovery system. If the ISS was to go from 3 to 6 crew, 4 Crew Quarters would replace 4 stowage racks in Node 2, and a Waste and Hygiene Compartment (toilet) would replace stowage racks in Node 3 (Fitts).

\section{Conclusions}

The purpose of the ISS is to perform research and one of the areas of research is on the effects of long duration space flight on humans. Areas of emphasis are: Loss of weight -bearing bone and muscle, Vestibular function, vestibularocular reflex and sensorimotor integration, Cardiovascular alterations, Radiation Hazards, Psychological and social issues and Health care in long-duration flight. (ReMAP). Each ISS Expedition crew adds greatly to what we know about long duration space flight. The ISS celebrated the second anniversary of continuous residency and permanent human presence in space Nov. 2, 2002. As data on the effects of long duration space flight on humans' accumulates it will become clear what the crew requires to stay healthy and function optimally on long duration space missions.

\section{ACKNOWLEDGMENTS}

Thanks go to the Crew Provisioning Working Group at JSC and the Operational Habitability group at JSC for providing insight into some of the challenges in living on-board the ISS.

\section{REFERENCES}

Miller, J., "Habitable Volume", VIPER Data.

Miller, J., Sorge, L., Miller, K. TOOTH ISS Rack Traffic Model and On-Orbit Topology.

NASA, Website: http://spaceflight.nasa.gov

NASA FPWG, Website: http://iss-WwW.jsc.nasa.gov/ss/issapt/ouipt/FPWG.html

NASA MIO, Multi-Increment Manifest Document, SSP 50110 Rev. F, August 2000.

CPWG Exp. 1, Logistics and Maintenance Crew Provisioning Expedition 1 Crew Debrief Minutes, April 2001.

CPWG Exp. 2, Crew Provisioning Post flight Debrief Questions Expedition 2 Crew Debrief Minutes.

CPWG Exp. 3, Crew Provisioning Post flight Debrief Expedition 3 Crew Debrief Minutes, January 2002.

Fitts, D., SLSD ISS Architectural Assessment, Briefing, February 2000.

ReMAP Task Force, Report by the NASA Biological and Physical Research, Research Maximization And Prioritization 
(ReMAP) Task Force to the NASA Advisory Council, August 2002.

SF6 Exp. 1, Operational Habitability Debrief Summary for International Space Station (ISS) Expedition 1, April 2001.

SF6 Exp. 2, Operational Habitability Debrief Summary for International Space Station (ISS) Expedition 2, August 2001.

SF6 Exp. 2, Operational Habitability POST FLIGHT Debrief Summary for International Space Station (ISS) Expedition 2, October 2001.

SF6 Exp. 3, Operational Habitability Post Flight International Space Station (ISS) Expedition 3, January 2002.

SF6 Exp. 4, Operational Habitability International Space Station (ISS) Expedition 4 Post Flight Debrief Summary, September 2002.

Walton, K., Interim Assembly Sequence, Revision F (SSCN XXXX), PICB Presentation, September 11, 2002. 